\title{
LA POESIA PROFÈTICA EN L'ORATIO AD COETVM SANCTORVM ${ }^{1}$
}

\author{
IGNASI VIDIELLA PUÑET \\ Universitat de Barcelona \\ ividiella@hotmail.es \\ ORCID: 0000-0003-3728-0571
}

RESUM

En l'Oratio ad coetum sanctorum, atribuïda a Constantí el Gran, trobem dues peces de caire poètic: un Oracle Sibil·lí $(8,217-250)$ i diferents versos de l'Ègloga 4 de Virgili, textos que, en un primer moment, semblaria que són inconnexos al context del discurs i que tan sols hi són transmesos com a exercici retòric. No obstant això, l'emperador empra aquestes dues composicions per demostrar que l'adveniment de Crist ja havia estat vaticinat anteriorment i les posa a tall d'exemple, l'una de tirada, l'altra intercalant-hi una anàlisi exegètica.

En aquest article, mirem de veure quina relació s'estableix amb la resta del discurs i de quina manera l'emperador Constantí mira d'enllaçar les diferents idees inserides en ambdós textos poètics per treure el màxim de profit possible al seu ús.

PARAULES CLAU: Constantí el Gran, discurs, poesia, Virgili, Sibil·la.

\section{PROPHETIC POETRY AT ORATIO AD COETUM SANCTORUM}

\section{ABSTRACT}

In the Oratio ad coetum sanctorum, attributed to Constantine the Great, we can find two poetical pieces: the Oracula Sibyllina 8 (217-250) and many verses of the Virgil's 8th Eclogues. At first glance, they seem unconnected with the rest of the speech and it looks like they serve as a rhetorical exercise. Nevertheless, the emperor used those texts to show that the coming of Christ had been foreseen before. He utilized them as example: the first one on the trot; the second one with an exegetical analysis alternated.

The aim of this article is to see how those are related with the rest of the speech. We want to show in which way Constantine linked the different ideas inside those both poetical texts to squeeze its use.

KEYWORDS: Constantine the Great, speech, poetry, Virgil, Sibylla.

L'Oratio ad coetum sanctorum és intitulat a la majoria de manuscrits com B $\alpha \sigma \iota \lambda \varepsilon ́ \omega \varsigma$

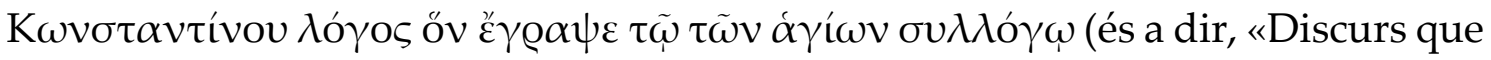
l'emperador Constantí composà per a l'assemblea dels sants»), i és transmès, gairebé sempre, entre la Vita Constantini i el Laus Constantini d'Eusebi de Cesarea. El bisbe, a la seva Vita Constantini $(4,32)$, anuncia que l'adjuntarà, en acabar el seu panegíric, amb el propòsit de demostrar que els traductors s'encarregaven de

\footnotetext{
${ }^{1 *}$ Volem agrair a les Dres. Montserrat Camps i Pilar Gómez l'haver llegit i millorat amb els seus comentaris aquest article.
} 
traslladar al grec els discursos que l'emperador proclamava en llatí. Aquest text va ser transmès als manuscrits, doncs, com un annex a la Vita Constantini de vegades, o bé en determinades ocasions com un cinquè i darrer llibre del panegíric. ${ }^{2}$ Així doncs, és gràcies a la tasca transmissora del bisbe de Cesarea, a la qual devem la pervivència d'una quantitat ingent de testimonis de vegades únics, que ha sobreviscut també aquest discurs fins als nostres dies.

El discurs es pot dividir en tres parts diferenciades. Al llarg de vint-i-sis capítols, tracta, en primer lloc, l'existència de Déu i l'ordenació de l'univers per la seva voluntat, així com la prova d'aquesta existència i la necessitat del culte cristià (§ 3-10); en segon lloc, un raonament introductori a la figura del Crist i la seva encarnació (§ 11-21). En la darrera part d'aquesta composició tripartida, es tracta la confrontació entre el cristianisme i la religió tradicional, l'enumeració d'alguns dels emperadors persecutors i el seu destí i de quina manera el triomf del propi emperador està vinculat a la seva fe en el Crist (§ 22-26). ${ }^{3}$

És en el segon d'aquests tres apartats que trobem dos textos poètics inserits en el discurs, i que han estat transmesos de manera diferent. El primer d'ells, un passatge d'un oracle de la Sibil.la (§ $18=$ Orac. Sibyllarum $8,217-250)$, d'interès per l'acròstic que crea l'inici de cada vers, és una tirada de trenta-quatre versos de caire apocalíptic emprats per justificar l'adveniment de Crist; el segon és un comentari de diferents versos de l'Ègloga 4 de Virgilit ${ }^{4}$ traduïts al grec, en el qual la transmissió no segueix el poema tal i com el conservem, sinó que ha estat alterat a conveniència. Així, com és recorrent en citacions i comentaris, hi ha alteracions en l'ordre intern dels versos però també en l'ordre compositiu. Això permet pervertir-ne l'ús, tot modificant-lo per tal de forçar el significat i contingut de cada vers a fi de crear un nou significat en aquest nou context.

Per tal de situar aquest discurs, subratllem que el text presenta diferents problemes a l'hora de ser datat i localitzat. Eusebi no el contextualitza, més enllà d'informar-nos que és una traducció grega d'un original llatí, i el propi text tampoc no dona gaires dades que puguin ser-nos d'utilitat. ${ }^{5}$ No és aquest l'espai ni el lloc per desenvolupar aquestes qüestions, ${ }^{6}$ però creiem, amb totes les reserves que calen, que Maraval (2010: XXII) podria encertar en establir que fou

${ }^{2}$ Només hi trobem diferència en aquells manuscrits on es conserven els excerpta dels versos sibil-lins, com és el cas del manuscrit Bodleianus F.06.1, el Toletanus 096-37 o el Venetianus gr. 260, per mencionar algun exemple; o, d'altra banda, del Savilianus thel. gr. 260, un florilegium del s. XV que només transmet l'Oratio juntament amb tres altres obres de Demetri Cidoni.

${ }^{3}$ Seguim, en aquest cas, la proposta de divisió que fan Rochette (2003: 218) i Barnes (2013: 116119); Decker (1976: 79-80) creu veure només dos temes principals: l'existència de Déu i la relació que s'estableix entre l'emperador i la divinitat.

${ }^{4}$ L'emperador cita i analitza la totalitat del poema, exceptuant-ne els versos 2-3; 11-14; $23-25 ; 28$ i $46-47$.

${ }^{5}$ Quant a aquesta problemàtica, $c f$. Decker (1976), Drake (1985) o Barnes (2001).

${ }^{6}$ Vid. Morlet (2018: 107-111) per a un detall dels diferents postulats. 
pronunciat a Nicomèdia, durant la Pasqua, tal com evoca el bell inici del text. ${ }^{7} \mathrm{Si}$ tal és així, això situa aquest discurs entre la batalla de Crisòpolis, el setembre del 324, i el Concili de Nicea, el 325.

Es tracta, a més, d'un discurs que no es pot emmarcar fàcilment en una única categoria literària, atès que l'orador hi combina l'homilia, la filosofia, el gènere apologètic i l'exegesi literària. ${ }^{8}$ Fins i tot, en el darrer tram del text, participa de l'exaltació de la seva pròpia figura i la connecta amb la de Crist, a qui pren com a aliat i reconeix el mèrit de les seves victòries en front dels enemics. Aquest és un punt interessant, que haurem d'observar més endavant, atès que Constantí es farà propi el senyal de la $\mathrm{creu}^{9}$ que va veure abans de la batalla del pont Milvi. ${ }^{10}$ Malgrat aquest fet puntual, el nivell de coneixement dels temes tractats al llarg del parlament és, en general, pobre, i mostra en diferents passatges un desconeixement parcial o total del contingut, no només bíblic, sinó també filosòfic que el propi emperador cita. ${ }^{11}$

Si ens centrem en els textos poètics, es tracta, com hem comentat abans, de dos textos en el bloc dedicat a la part cristològica del text: els versos pertanyents als Oracula Sibyllina $(8,217-250)$, que ocupen tot el capítol 18 sencer; i el comentari de la traducció, lliure i tendenciosa, dels versos de l'Ègloga 4 de Virgili, que coincideixen amb els capítols 19-21. Aquestes dues peces poètiques s'emmarquen en la reiteració que fa l'emperador quan diu que la passió i l'adveniment de Crist havien estat anunciats pels profetes (§ 16). De fet, tot just en començar la seva dissertació, l'emperador manifesta que és la revetlla de la Passió, i recorda que aquesta ja ha estat anunciada pels oracles ([...] $\theta \varepsilon \sigma \pi i ́ \sigma \mu \alpha \sigma \iota \pi \varrho 0 \sigma \alpha \gamma o \varrho \varepsilon v o ́ \mu \varepsilon v o \varsigma$, $\S 1,1)$. Aquesta encarnació, com especificarà més endavant, havia estat predita per tal de destruir els fruits de la injustícia i abolir la superstició. Tal afirmació li servirà d'excusa per poder introduir, abans dels textos que ens interessen, la figura de Moisès i Daniel.

En primer lloc, Constantí explica que ciutats com Memfis i Babilònia, que

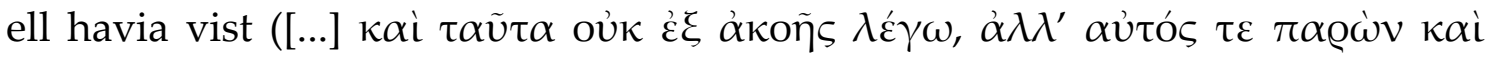

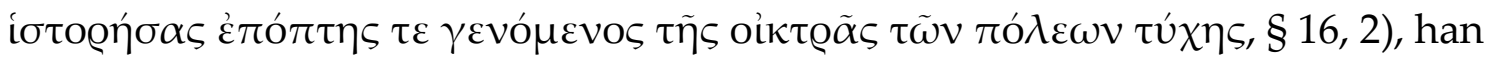
caigut per voluntat de Déu, i que va ser Moisès qui va vèncer el faraó. La figura de Moisès, que Constantí empra com a exemplum maiorum, servirà a l'emperador per posar un referent de personatge vencedor - com ell mateix - en virtut de la seva aliança amb la divinitat. ${ }^{12}$ L'esment d'aquest personatge és oportú, atès que

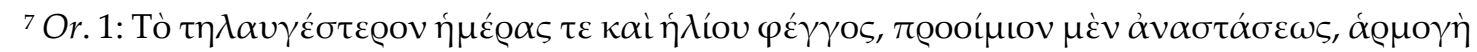

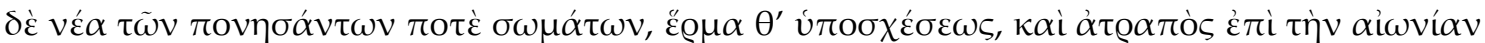

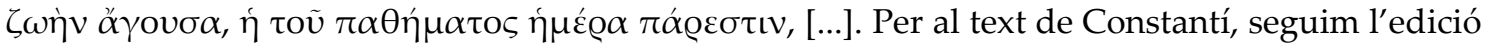
de Heikel (1902).

8 Barnes (1981: 75).

9 Vid. Edwards (1999: 257-258).

${ }^{10}$ VC 1, 27-32.

${ }^{11}$ Maraval (2010: 226).

${ }^{12}$ Miglietta (2000: 247) només interpreta com a figures profètiques Daniel, la Sibillla i Virgili. Això no obstant, el fet que la figura de Moisès aparegui en aquest punt del discurs, i atesa la 
l'emperador es vincula amb el lloc que ha testimoniat i, alhora, li serveix d'introducció en les figures veterotestamentàries i de preludi per parlar del profeta Daniel, de tal manera que ocupa aquests dos capítols (§ 16-17) emprant referents profètics de l'Antic Testament, tot i que la figura de Moisès no hagi complert aquest propòsit. ${ }^{13}$

Per parlar de Daniel, l'emperador relata que el qui fou un dels quatre grans profetes rebé com a càstig per les seves profecies i la seva pietat el ser llençat als lleons ${ }^{14}$ per part de Cambises - segons la versió de l'orador (§ 17, 2). Tanmateix, existeixen dos elements que podem observar: en primer lloc, hi ha la inexactitud de la versió veterotestamentària i el poc coneixement per part de l'emperador dels referents que empra. Allò que és atribuït a Cambises per part de l'emperador, la tradició ho ha imputat sempre a Cir (Dn. 14, 31-42). Veiem, però, que, malgrat tot, recorda les parts més rellevants de l'escena, com és el final en què els lleons no devoren el profeta sinó els persecutors per ordre de Déu.

En segon lloc, trobem la introducció al tema profètic. Constantí, que ja ha dit que els profetes havien anunciat l'arribada $(\S 16,1)$, empra la figura de Daniel com a referent $(\S 17,2)$, encara que no esmenta cap profecia en concret en relació amb el Crist. Daniel, que és un dels personatges més rellevants a l'Antic Testament, serveix novament a l'emperador d'exemplum maiorum, tal com havia emprat abans la figura de Moisès. Diu que va fer vaticinis, però sense concretarne cap i que, fruit d'això i de la seva pietat, va ser condemnat al martiri. La història serveix a l'emperador per introduir la temàtica; gairebé com una excusa. Constantí s'ha vinclat, voluntàriament, amb la tradició judeocristiana en esmentar dos referents profètics vencedors de la persecució dels enemics, malgrat no dir quins foren els seus vaticinis. Acte seguit, farà referència al vaticini de la Sibillla eritrea; Constantí citarà, de tirada i de forma literal, el text que s'atribueix a la Sibillla, de manera que dedicarà tot el capítol 18 a presentar el personatge $i$ al seu vaticini.

El primer que cal destacar és l'oportunitat d'aquest recurs: Constantí no es limita a esmentar els elements bíblics que li puguin ser favorables, sinó que recorre als textos pagans. ${ }^{15}$ Aquest recurs el trobem a bastament testimoniat a Eusebi de Cesarea o a Climent d'Alexandria, els quals sovint farceixen el seu propi discurs de cites paganes ${ }^{16}$ per tal que el cristianisme sigui compatible amb

coneguda vessant profètica del personatge, fa que hom pugui establir una doble funció: s'empra un profeta que, afavorit per la divinitat, és vencedor davant d'enemics poderosos.

${ }^{13} \mathrm{Amb}$ tot, la figura de Moisès és vinculada estretament, en el cristianisme, amb la figura del Crist, i en podem veure ja mostres al Nou Testament, Ac 7: 39-53.

${ }^{14}$ La figura del lleó serà recollida més endavant per Constantí, atès que apareix novament al poema de Virgili (Or. 20, 2). Constantí veurà l'oportunitat de posar en comú ambdues referències en fer esment als persecutors del cristianisme i hi emprarà la figura dels lleons.

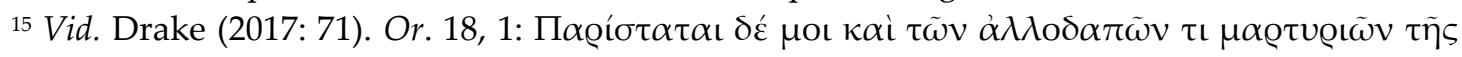

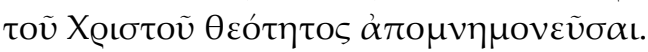

${ }^{16}$ Vidiella (2017: 78). 
la lectura de textos de tradició grega. ${ }^{17}$ Esdevenen un sol riu que beu de diferents tradicions, que serveixen als cristians per adoptar gent de cultura, que reconeix els diferents relats i que pot arribar a acceptar la unificació de les diferents tradicions.

Així, els primers personatges esmentats per Constantí són Moisès i Daniel, els quals ell no pot fer-se propers de cap manera, ni etnogràficament ni culturalment, atès que pertanyen a la raça «assíria», tal i com anomena a l'antic poble de l'aliança $(\S 20,5)$. Això no obstant, es vincula amb ells mitjançant la unió cultual que els uneix amb Crist. El segon dels vaticinis, d'altra banda, és el d'una estrangera, a nivell etnogràfic i cultual, però no a nivell cultural, atès que aquella era grega i, per tant, pertany a la pròpia tradició de l'emperador romà. És un testimoni absolutament útil: és sacerdotessa d'Apol·lo, com especifica el propi emperador, fent incidència en la seva desconnexió amb el culte cristià, però, tanmateix, profetitza la figura de Jesús.

El propi cant sibil-lí transmès és interessant: Constantí ens llega una tirada de trenta-quatre versos (217-250) del llibre VIII que formen l'acròstic 'I

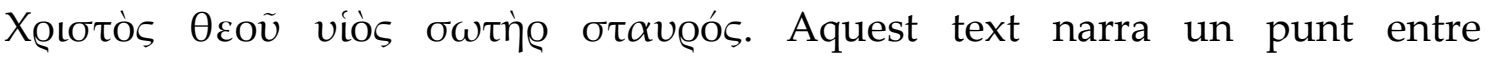
l'adveniment de Crist i el Judici Final, on es diu que, gràcies a l'encarnació del primer, els mortals veuran Déu, s'esdevindrà la resurrecció dels morts i la destrucció de la terra i, en darrer terme, els escollits veuran la fusta ( $\xi u ́ \lambda o v)$, com a sinècdoque de la creu, i la banya desitjada. Finalment, els dos darrers versos serveixen per informar, mitjançant l'acròstic, que ha estat anunciat aquest adveniment. ${ }^{18}$ L'oracle manté un tipus de llenguatge volgudament obscur i deliberadament apocalíptic, propi de l'embriagament de la inspiració divina en què fou pronunciat $(\S 18,2)$.

És pertinent de tenir en compte que, si aquest text fou pronunciat en llatí, tal i com Eusebi de Cesarea diu que va succeir, ${ }^{19}$ aquests versos sibil-lins en grec tindrien poc sentit davant del seu auditori. ${ }^{20}$ No se'ns fa difícil pensar que es va limitar a pronunciar l'acròstic i que la resta de text va ser afegida en el procés de traducció. Sí que és curiós, però, que la darrera paraula de l'acròstic sigui el mot

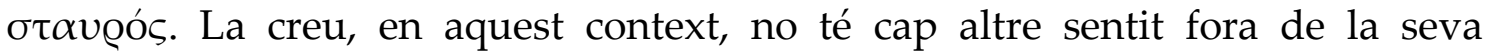
vinculació amb aquella creu que l'emperador ha fet emblema propi un cop assolida la victòria del pont Milvi i que se li havia aparegut en una visió. ${ }^{21} \mathrm{De}$ fet, la paraula no encaixa sintàcticament en l'acròstic i no està transmesa, per

\footnotetext{
${ }_{17}$ Es pot veure una defensa d'aquest fet en Basili de Cesarea; vid. Gómez Cardó (2018).

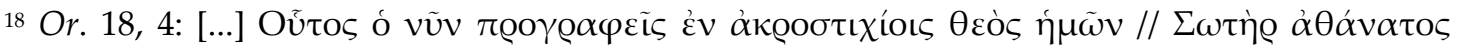

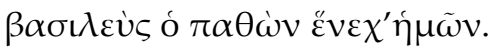

${ }^{19}$ Cal recordar que aquest text és annexat a la Vita Constantini per demostrar que l'emperador feia els discursos en llatí i després la cancelleria imperial els traduïa al grec. Vid. VC 4, 32.

${ }^{20}$ Edwards (2015: 186).

${ }^{21}$ VC 1, 18.
} 
exemple, en la traducció d'Agustí, que és l'altra via per la qual ens ha arribat aquest text. ${ }^{22}$

La fórmula 'Jesús Fill de Déu Salvador' tenia tradició entre els cristians i permetia ser abreujada en $i \theta \chi v ́$, "peix», símbol del colllectiu. ${ }^{23}$ Això no obstant, Constantí té la voluntat de pronunciar un discurs que manté connotacions polítiques i referències a la seva pròpia persona. En aquest parlament, al final de l'acròstic sibil-lí, hi fa aparèixer la creu, que s'ha fet seva. Així i tot, és l'única vegada que s'esmentarà la creu en aquest discurs. Enlloc més no cita de manera directa aquest símbol, més enllà d'aquell $\xi u ́ \lambda$ ov que apareix, justament, en el

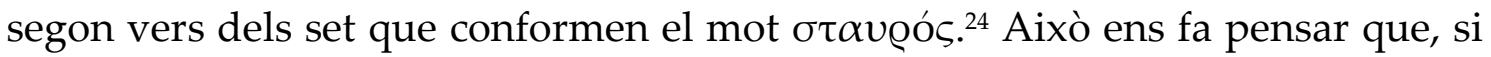
aquests versos no foren pronunciats completament, sinó que només se'n recità l'acròstic, potser va ser un afegit del propi emperador que després el traductor va haver de maldar per introduir i desenvolupar.

El personatge de la Sibil-la havia estat ja emprat anteriorment pels cristians. Justí, en la seva Apologia 1, 44, l'esmenta com a coneixedora d'un bé suprem que és prohibit i castigat amb la mort a qui en llegeixi els escrits. També la trobem a Atenàgores (Leg. 30) i a Lactanci, clar influent de Constantí, que transmet altres llibres de la Sibil.la. ${ }^{25}$ Atès el seu ús anterior i que alguns polemistes deien que aquests testimonis eren inventats, ${ }^{26}$ Constantí es remet a dues veus de summa auctoritas per donar veracitat al testimoni: en primer lloc, invocarà la figura de Ciceró $(\S 19,2)$ per dir que ell també va conèixer aquesta Sibil-la - si bé no va fer, evidentment, referència a aquests versos. De fet, per bé que Ciceró parla del furor en el seu text, ${ }^{27}$ Constantí descriu que la Sibil-la, tot i servir l'estupidesa antiga, va ser omplerta per la inspiració divina i va profetitzar l'adveniment de Jesús $(\S 19,2)$. El segon testimoni serà Virgili.

Constantí usa el recurs de la temporalitat per tal de garantir la veracitat de la Sibil-la. Segons ens explica, pertany a la sisena generació després del diluvi $(\S 18,1)$, i Ciceró, que fou mort per Antoni, ja emprà els seus textos. Al seu torn, Antoni fou vençut per August, que precedí Tiberi, durant el regnat del qual es produí l'encarnació de Crist. ${ }^{28}$ Així doncs, en l'afany de situar el personatge, l'emperador recorre a tot un seguit d'idees que encadena $i$, al seu parer, cadascuna d'aquestes avala l'anterior. Fa servir el pes del passat per donar-li segell de veracitat. De fet, és en el regnat de Tiberi quan, diu, «esclatà

${ }^{22}$ Aug. Ciu. 18, 23; vid. Guillaumin (1978: 198), que defensa que la diferència rau en dues famílies manuscrites dels Oracula Sibyllarum i que considera que Agustí i Constantí no llegiren el mateix.

${ }^{23}$ Miglietta (2000: 251).

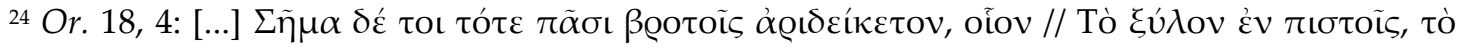

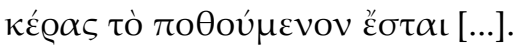

${ }^{25}$ Lact. Inst. 4, 18, 13; 18, 17; 18, 19; 19, 4, 10.

${ }^{26}$ Vid. Orig. Cels. 7, 53.

${ }^{27}$ Cic. div. 1, 2, 4; 1, 36.

${ }^{28}$ Aquest regnat és identificat també per Eusebi de Cesarea $(P E 5,17,13)$ com el moment del naixement de Crist. Segons el bisbe, va ser aleshores que moriren tots els dimonis, i amb ells el déu Pan, que il-lustra amb una cita de Plutarc (Moralia 29, 418e-420a). 
l'adveniment» (§ 19, 3), la qual cosa Virgili havia recollit en el primer vers que l'emperador cita de l'Ègloga 4, en dir que «apareix una nova munió d'homes»

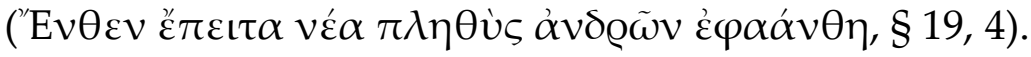

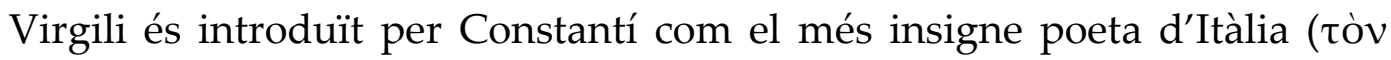

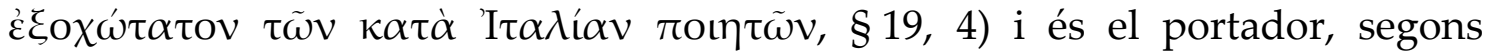
l'emperador, d'una nova profecia que vaticina l'adveniment de Crist. El de Màntua, a més, és enllaçat en aquest entramat de textos profètics mitjançant el seu propi poema i serveix per partida doble els seus interessos: com a poeta que coneix la Sibilla (la cumana, en aquest cas) ${ }^{29}$ i com a portador d'una profecia. Això reforça la idea unitària del sentit dels dos textos i enllaça de manera molt forta el sentit d'ambdues peces poètiques, a part de vincular la realitat romana, mitjançant el gran poeta, amb la realitat cristiana.

Al llarg de dos capítols, l'emperador va fent un comentari exegètic del text de Virgili, citant versos i fent una interpretació del que hi diuen, amb una clara intenció messiànica. Aquests versos citats, tal i com ha estudiat Rochette (2003), no mantenen l'ordre del text virgilià, i la traducció, que segons l'estudiós belga no va ser feta pel mateix personatge que va traduir la resta del discurs, ${ }^{30}$ té un biaix absolutament intencionat cap a un propòsit apologètic. L'autor del text considera que Virgili era del tot conscient del que feia, però que es mantingué ambigu en la seva producció per tal de no ser castigat pels governadors del seu temps, que actuen com a lleons. De fet, és aquí on tornem a trobar els lleons que ja havíem vist en la part dedicada al profeta Daniel. L'emperador, en refer i col-locar els versos virgilians on li van millor, sense respectar-ne l'ordre original, diu que en venir el Crist $(\S 20,1)$ la terra generarà de manera espontània $i$, quan les cabres seran plenes, l'adveniment no permetrà que els lleons esbocinin els ramats $(\S 20,2)$. Així, veiem que de nou es torna a fer menció a uns lleons l'objectiu primer dels quals hauria de ser el de destruir quelcom protegit per la divinitat: ara, les cabres, que no atacaran per l'adveniment del Crist; abans, aquells lleons que no havien volgut atacar Daniel, per mandat diví. Aquí, en el text virgilià, els lleons, que són assimilats posteriorment amb els governadors de la cort imperial per l'exegeta impliquen la desaparició del poder de la cort per deixar únicament la figura imperial, atès que ja s'ha produit l'aparició de Crist. En aquell altre apartat que parla del profeta Daniel, Déu protegia qui anunciava aquest adveniment provocant, fins i tot, la destrucció dels seu perseguidor $(\S 17,4)$.

Malgrat tot, Constantí sembla tirar-se pedres al propi teulat perquè, si bé diu que el text virgilià anunciava aquest adveniment, i ja a l'inici del discurs ( $§ 1$, 2) rememorava que això havia estat vaticinat per profetes, l'emperador recorda que Virgili no era un profeta, sinó un poeta $(\S 20,8) \cdot{ }^{31}$ Així, si bé Constantí fou un

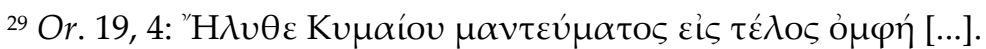

${ }^{30}$ Rochette (2003: 219).

${ }^{31}$ Courcelle (1957: 314).
} 
dels impulsors de la consideració profètica del poeta, ${ }^{32}$ ell mateix li treu aquesta categoria. Considerem, però, que allò que el fa profeta, o com a mínim fa que se l'inclogui entre els transmissors de profecies és, precisament, la poesia. L'autor del comentari exegètic del poema virgilià ens diu que va emprar la seva facultat poètica per narrar l'avenir ( $(20,8)$. I és probable que el fet que el text, volgudament coincident amb la realitat, estigui en forma de poesia faci que el poeta sigui considerat com un profeta, tot i que no ho sigui.

Lactanci, preceptor en la cort constantiniana, que també havia posat en paral-lel - encara que no in extenso com en el text que ens ocupa- els oracles sibil-lins (el tercer llibre, en el seu cas) i les Geòrgiques virgilianes, ${ }^{33}$ afirma que el valor de la veritat poètica rau en com la poesia s'aproxima a la veritat de les Escriptures. ${ }^{34}$ I és aquí on trobem una bona ocasió per comparar els versos virgilians amb el que ha estat pronosticat per la Sibilla i el que havia passat amb els que intentaren matar Daniel. Així, Virgili no és un profeta stricto sensu, sinó que ho és en virtut de l'obra produïda.

L'existència d'un text poètic que parli de l'adveniment d'un infant permet als cristians recordar les profecies de l'Antic Testament, poètiques en la seva gran majoria, i fa que els oients trobin la relació entre la poesia i la profecia com a pertinent. L'emperador ha esperat a posar a Virgili en el darrer lloc. Primer ha mencionat Moisès i més tard ha parlat de Daniel, del qual no n'ha citat cap text ni profecia; més tard ha posat els versos Sibil-lins, si bé hem dit que segurament no van ser recitats en el moment de pronunciar el discurs, però el fet que fossin en vers i l'explicació de l'acròstic ja creaven una bona porta d'entrada a considerar Virgili poeta, com a autor, i profeta, en funció, tot i que encobert pels temps que li tocaren viure $(\S 20,8)$.

Així doncs, com a conclusió, podem assenyalar que l'Oratio ad coetum sanctorum, text pronunciat per Constantí en llatí i traduït més endavant al grec pels secretaris de la cancelleria, segons reportà Eusebi, recull dos poemes amb finalitats profètiques. D'aquests dos, un segurament no fou recitat més enllà de l'acròstic que formen els versos pel fet d'estar en grec. Del segon, se'n va fer una manipulació voluntària de l'ordre dels versos per tal de donar un sentit específicament messiànic al text. Ambdós es justifiquen en un context que necessita recordar que l'adveniment de Crist ja fou profetitzat i l'autor empra diferents recursos amb una finalitat gairebé holística que cerca les diferents tradicions a fi de fer-les harmòniques amb la voluntat de demostrar els vaticinis de l'adveniment. Així, esmenta els profetes veterotestamentaris i, seguidament,

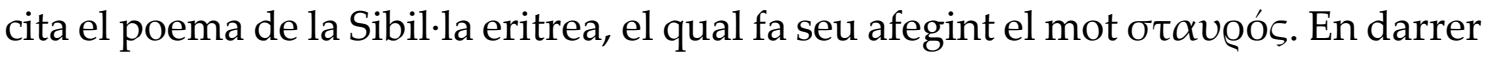
terme, empra la poesia virgiliana. Virgili, que com el mateix emperador recorda

\footnotetext{
32 Rochette (2003: 232).

${ }^{33}$ Lact. Inst. 1, 5 i 11; 7, 24.

${ }^{34}$ Cf. Swift (1968: 146).
} 
és un poeta, exerceix de profeta en haver fet la seva poesia pròxima a la veritat revelada a les escriptures.

\section{BIBLIOGRAFIA}

BARNES, T. D. (1981), Constantine and Eusebius, Cambridge i Londres, Harvard University Press.

BARNES, T. D. (2001), «Constantine's Speech to the Assembly of the Saints: place and date of delivery", The Journal of Theological Studies, 52(I), 26-36.

BARNeS, T. D. (2013), Constantine. Dynasty, Religion and Power in the Later Roman Empire, Chichester, Wiley-Blackwell.

COURCELle, P. (1957), «Les exégèses chrétiennes de la quatrième Églogue», Revue des Études Anciennes, 59(3-4), 294-319.

DECKER, D. (1976), «Le Discours à l'assemblée des saints attribué à Constantin et l'œuvre de Lactance», a Lactance et son temps. Recherches actuelles. Actes du IVe colloque d'études historiques et patristiques. Chantilly 21-23 deptembre 1976, Fontaine, J. i Perrin, M. (eds.), París, Beauchesne, 75-87.

DraKe, H. (1985), «Suggestions of Date in Constantine's Oration to the Saints», The American Journal of Philology, 106(3), 335-349.

DrAKe, H. (2017), A Century of Miracles. Christians, Pagans, Jews, and the Supernatural, 312-410, Nova York, Oxford University Press.

EDWARDS, M. (1999), "The Constantinian Circle and the Oration to the Saints», a Apologetics in Roman Empire. Pagans, Jews and Christians, Edwards, M., Goodman M. i S. Prince (eds.), Oxford, Oxford University Press, 251-275.

EDWARDS, M. (2015), Religions of the Constantinian Empire, Nova York, Oxford University Press.

GÓMEZ CARDÓ, P. (2018), «Apuntes de un sofista cristiano en torno a la literatura griega: Ad adulescentes de Basilio el Grande», Emerita, 86(2), 277-301.

Guillaumin, M.-L. (1978), «L'exploitation des Oracles Sibyllins par Lactance et par le Discours à l'Assemblée des Saints», a Lactance et son temps. Recherches actuelles. Actes du IVe colloque d'études historiques et patristiques. Chantilly 21-23 deptembre 1976, J. Fontain, J. i Perrin, M. (eds.), París, Beauchesne, 185-200.

HeIKEL, I. A. (1902), Eusebius Werke, Leipzig, J.C. Hinrichs'sche Buchhandlung.

MaraVAL, P. (2010), Constantin. Lettres et Discours, París, Les Belles Lettres.

MiglietTA, M. (2000), «La conoscenza profetica del vero nella Oratio ad sanctorum coetum di Costantino Magno», a Gli arconti di questo mondo. Gnosi: politica e diritto. Profili di simbolica politico-giuridica, Bonvecchio, C. i Tonchia, T. (eds.), Trieste, Università di Trieste, 245-281.

MORLET, S. (2018), «À propos du prince théologien. Constantin, Eusèbe, et le discours $\grave{A}$ l'assemblée des saints», a Le prince chrétien. De Constantin aux royautés barbares (IVe-VIIIe siècle), Destephen, S., Dumézil, B. i Inglebert, H. (dirs.), París, Association des Amis du Centre d'Histoire et Civilisation de Byzance, 101-125.

RochetTE, B. (2003), «De la Rome païenne à l'Empire Chrétien: la traduction grecque de la Quatrième Églogue dans le Discours à l'assemblée des saints attribué à Constantin», a Hommages à Carl Deroux, V (christianisme et Moyen Âge. Néolatin et survivance de la latinité), Defosse, P. (ed.), Brussel·les, Latomus, 217-232. 
SWIFT, L. J. (1968), «Lactantius and the Golden Age», The American Journal of Philology, 89(2), 144-156.

VIDIELLA, I. (2017), «Algunas muestras de Homero en la Praeparatio Euangelica de Eusebio de Cesarea», Studia Philologica Valentina, Anejo 1, 77-86. 